\title{
A DESTRUIÇÃO DA EDUCAÇÃO NO BRASIL E A LUTA EM DEFESA DA ESCOLA PÚBLICA
}

Prof. Sebastian Sanchez Martin*

\section{RELEMBRANDO}

Em conferencia pronunciada no Clube de Engenharia, em 1957, dizia o velho mestre Anísio Teixeira:

"A situação educacional brasileira apresenta-se como uma pirâmide, em que a base não chega a ter consistência e solidez de tão tênue que é, logo se afilando, mais à maneira de um obelisco do que mesmo de uma pirâmide. Tal aspecto manifesta-se desde a escola primária.

Para uma população escolar de 7 a 11 anos de idade, num total de 7.595 .000 , a escola primária acolhe 4.921 .886 , ou seja, cerca de $70 \%$. Destes, porém encontram-se no $1^{\circ}$ ano 2.664 .121 , quando ali só se deviam encontrar 1.600 .000 (grupo de idade de 7 anos), no $2^{\circ} 1.075 .792$, quando ai se deviam achar 1.500 .000 , no $3^{\circ} 735.116$, onde deviam estar I.500.000, no $4^{\circ}$ e $5^{\circ}$ anos 466.957 , quando ai deviam estar 1.480 .000 ...

Ora, ai temos o primeiro aspecto pelo qual se verifica como e quanto o ensino primário vem sendo desvirtuado. Considerando-o puramente preparatório às fase ulteriores da educação, descuidamo-nos de organizá-lo para efetivamente atender a todos os alunos, seja qual for a capacidade intelectual de cada um, e vimos, ao contrário, mantendo a velha organização seletiva de escola propedêutica. $O$ característico da organização das escolas para finalidade seletiva é o menosprezo às diferenças individuais, ou a utilização das diferenças individuais apenas para eliminar os reputados incapazes. Os que não se revelarem capazes, são reprovados, tornando-se ou repetentes, ou excluídos. Nessa organização cabe ao aluno adaptar-se ao ensino e não o ensino ao aluno. ..."

Bem que valeria a pena continuar citando a bela palestra do

*Professor Adjunto do Departamento de Educaçāo, Centro de Humanidades, Camapus II, UFPB. 
ilustre pedagogo baiano Anísio Teixeira. As suas considerações a respeito da situação do ensino e da escola naquela época são pertinentes hoje e ainda o serão por muito tempo. Mas, 40 anos se passaram e, muito embora o país tenha mudado bastante, as questões relativas à educação, a não ser a da universalização do ensino, mudaram e não precisamente para melhor.

\section{A QUESTÃO DO FLUXO ESCOLAR}

A Escola Pública Brasileira continua marcada por uma profunda crise que, se por um lado, reflete as condiçoes gerais da sociedade brasileira, por outro, tem também a sua problemática específica. O Brasil figura entre as 12 maiores economias do mundo, milhões de pessoas, no entanto, são, ainda, excluídas dos benefícios sociais básicos, entre eles a educação. O direito ao exercício da cidadania por parte de tantos milhões de brasileiros fica, por isso mesmo, cerceado. Os dados sobre o analfabetismo, a evasão escolar (ou melhor, a exclusão escolar, como já muito bem colocava Anísio Teixeira) e a repetência são, no Brasil, alarmantes e, no Nordeste, indignos de serem mencionados. De fato, das 3.575.534 crianças sem escola existentes no Brasil, segundo dados do IBGE (1990), 2.526.294 correspondem ao Nordeste. O que significa a taxa de escolarização mais baixa do Brasil, isto é $71,02 \%$. Uma olhada rápida ao quadro abaixo é suficiente para ver a disparidade existente entre as regiões brasileiras no que diz respeito à taxa de escolarização. Diante de semelhante quadro só cabe uma atitude: o problema tem de ser urgentemente enfrentado.

CRIANÇAS DE 7 A 14 ANOS FORA DA ESCOLA POR REGIÃO

\begin{tabular}{c|r|r|r|r}
\hline Regiáo & $\begin{array}{c}\text { Populaçao } \\
\text { Escolar }\end{array}$ & Matricula & $\begin{array}{r}\text { Crianças } \\
\text { sem Escola }\end{array}$ & $\begin{array}{c}\text { Taxa de } \\
\text { Escolari- } \\
\text { zacáo }\end{array}$ \\
\hline Norte & $\mathbf{1 . 8 0 8 . 0 4 7}$ & 1.565 .776 & 242.271 & $86,60 \%$ \\
Nordeste & $\mathbf{8 . 7 1 7 . 0 8 1}$ & $\mathbf{6 . 1 9 0 . 7 8 7}$ & $\mathbf{2 . 5 2 6 . 2 9 4}$ & $\mathbf{7 1 , 0 2 \%}$ \\
Centro-Oeste & $\mathbf{1 . 9 7 4 . 0 6 6}$ & 1.855 .241 & 118.825 & $93,98 \%$ \\
Sudeste & $\mathbf{9 , 8 2 1 . 9 0 5}$ & $9.457,119$ & 364.786 & $96,29 \%$ \\
Sul & 3.723 .147 & 3.399 .788 & 323.358 & $91,31 \%$ \\
BRASIL & $\mathbf{2 6 . 0 4 4 . 2 4 6}$ & $\mathbf{2 2 . 4 6 8 . 7 1 2}$ & $\mathbf{3 . 5 7 5 . 5 3 4}$ & $\mathbf{8 8 , 2 7 \%}$ \\
\hline
\end{tabular}


A iniqüidade do sistema aparece marcada, dentre outras variáveis, pela mesma absurda irregularidade da pirâmide que formariam os números da escolarização se escalonados por série. Isto é, observando o desenho abaixo, se aceitarmos um indice de mortalidade infantil normal, a pirâmide correta deveria ser a "pirâmide larga", mas, de fato, a pirâmide hoje existente é a "pirâmide estreita" 
MATRÍCULA POR SÉRIE NUM MUNICÍPIO DO INTERIOR PARABBANO

\begin{tabular}{|c|c|c|}
\hline $4^{a}$ & 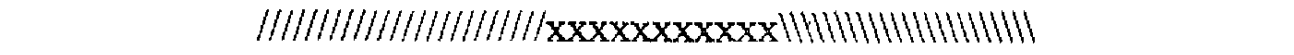 & 534 \\
\hline $3^{a}$ &  & 675 \\
\hline $2^{\mathrm{a}}$ & 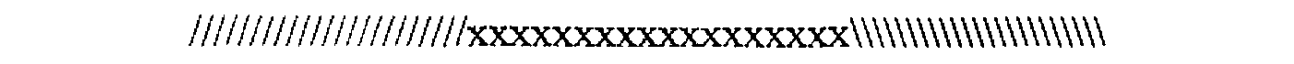 & 897 \\
\hline $1^{a}$ & 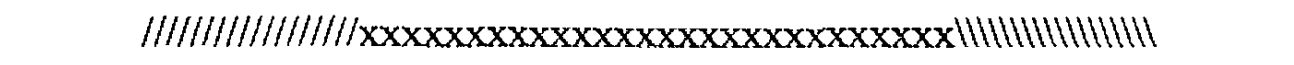 & 1.394 \\
\hline Alfabetização &  & 2.503 \\
\hline
\end{tabular}

Legenda: xooos a pirâmide como é, de fato

IIIINiM a pirâmide como deveria ser. 
A quantidade de crianças com 6 anos realmente existente e que deveriam estar na lase de alfabetização, não é quase o dobro das crianças com 7 anos (que deveriam estar na $1^{\text {ia }}$ série) e $0 \mathrm{n}^{\circ}$ destas nāo é quase o dobro das crianças com 8 anos (que deveriam estar na $2^{a}$ séric). A quantidade de crianças existentes em cada uma das faixas etárias correspondente a cada série é, na realidade, aproximadamente a mesma, uma vez que a variação da taxa de natalidade de ano para ano é quase imperceptível, e a diferença do índice de mortalidade intantil, de ano para ano, nesse período também é pequena. Mas, observando tanto a pirâmide acima como o quadro abaixo, observamos que a diferença do $n .^{\circ}$ de matrículas da alfabetização para $1^{1}$ série e desta para a $2^{0}$ é de quase o dobro. É ai que está o grande e perverso funil que impede uma progressão homogênea e justa do fluxo de crianças nos primeiros degraus do sistema escolar.

QUADRO DA MATRICULA POR SÉRIE NUM MUNICÍPIO DO INTERIOR PARAIBANO

\begin{tabular}{|c|r|r|r|r|r|}
\hline & \multicolumn{2}{|c|}{$\begin{array}{c}\text { Matriculas } \\
\text { Novas }\end{array}$} & \multicolumn{2}{c|}{$\begin{array}{c}\text { Matrículas } \\
\text { Repetentes }\end{array}$} & \multirow{2}{*}{ Total } \\
\cline { 2 - 5 } & Masc. & \multicolumn{1}{c|}{ Fem. } & Masc. & Fem. & \multicolumn{1}{c|}{ Tom } \\
\hline $4^{\mathrm{a}}$ & 151 & 203 & 28 & 46 & 428 \\
$3^{\mathrm{n}}$ & 201 & 284 & 17 & 43 & 545 \\
$2^{\mathrm{a}}$ & 294 & 381 & 73 & 70 & 828 \\
$1^{\mathrm{a}}$ & 510 & 526 & 161 & 142 & 1.339 \\
Alfabetização & 1.432 & 1142 & - & - & 2.574 \\
\hline TOTAL & 2.588 & 2.536 & 279 & 301 & 5.704 \\
\hline
\end{tabular}

\section{A QUESTÃO DOS RECURSOS}

Os recursos destinados à educação não garantem um padrão mínimo de qualidade. No tocante à questão salarial todos sabem que os salários não são condizentes com a exigências da profissão em nenhum dos níveis do sistema educativo e muilo menos no ní- 
vel da educação básica onde os salários mínimos dos professores em praticamente todos os estados são, ainda, irrisórios. Pior ainda é constatar que boa parte dos professores e professoras nem o salário mínimo recebe. A situação de penúria é tal que alguns professores vão participar de encontros e cursos de reciclagem com a finalidade, talvez principal, de aproveitar do almoco oferecido no local de treinamento. $O$ corte de verbas para a pesquisa e a extensão impede o desenvolvimento de novos projetios de qualificação dos professores, que deveria ser uma tarefa permanente, contínua, e inibe os projetos atualmente em execução. $O$ descaso para com a manutenção do patrimônio público atinge limites nunca antes atingidos. No referente às edificacões escolares chega-se a constatar, inclusive, o risco de vida provocado pelo perigo de desmoronamento de prédios. A falta de merenda escolar, principalmente nas áreas mais carentes do Brasil, desestimula a freqüência e afasta, definitivamente, grande quantidade de alunos da escola fundamental. Esta situação econômica global gera, necessariamente, um desequilíbrio social no interior do sistema educacional que deve ser remediado. Esse desequilíbrio inadmissível constata-se na enorme disparidade existente no tocante à taxa de (des)escolarização da populaçāo, em geral e da (des)qualificacão do professor, em particular.

\section{A QUESTÃO DA (DES)QUALIFICAÇÃO}

Pode-se, facilmente, constatar que, principalmente na zona rural, boa parte das professoras do ensino básico é composta de profissionais dos mais variados ramos da produção e dos serviços que dedicam, também, parte, somente parte, do seu tempo ao trabalho da docência. A maior parte do tempo é dedicado aos mais variados trabalhos, sejam eles desenvolvidos no próprio lar ou na lavoura ou ainda em algum ramo do artesanato que impedem à professora de se dedicar, minimamente, aos trabalhos da escola, quanto menos entrar num processo de formação permanente.

Essa realidade é, ainda, agravada pelo nível de formacão inicial, muito deficiente. Num levantamento de dados realizado por uma das bolsistas engajadas no projeto de extensão desenvol- 
vido pelo Departamento de Educação da Universidade Federal da Paraíba, constatamos que das 237 professoras do sistema municipal de ensino, num município vizinho a Campina Grande, 51 professores(as) não têm, ainda, o $1^{\circ}$ grau completo, outras 60 possuem somente o $1^{\circ}$ grau completo. Isto é, 111 professoras, o que equivale a dizer aproximadamente o $50 \%$ do corpo docente, está muito abaixo dos níveis mínimos de formação exigidos para o exercício do magistério. Para completar o quadro acrescentamos: 12 professoras têm o $2^{\circ}$ grau incompleto e outras $4302^{\circ}$ grau completo; 22 o Logos incompleto e 46 o Logos completo, somente 3 (três) tem pedagógico. Pode-se concluir: nível de formação inicial dos professores totalmente inadequado, insuficiente ao exercício do magisté. rio. Veja-se o quadro abaixo.

NÍVEL DE FORMAÇÃO dOS PROFESSORES MUNICIPAIS DE BOQUEIRÃO-PB"

\begin{tabular}{|c|c|c|c|c|c|c|c|}
\hline \multicolumn{2}{|c|}{$1^{\circ}$ Grau } & \multicolumn{2}{c|}{$2^{\circ}$ Grau } & \multicolumn{2}{c|}{ Logos } & Pedagógico & Total \\
\cline { 1 - 6 } Incompleto & Completo & Incompleto & Completo & Incompleto & Completo & & \\
\hline 51 & 60 & 12 & 43 & 22 & 46 & 03 & 237 \\
\hline
\end{tabular}

\section{A QUESTÃO IDEOLÓGICA}

A escola, no Brasil, estruturou-se de forma tradicionalmente oligárquica não somente em função do contieúdo transmitido nas salas de aula, mas também porque a cada grupo social correspondia um tipo próprio de escola, destinado, dependendo do caso, a formar geraçoes de dirigentes, por uma lado, ou trabalhadores. manuais, por outro. Essa escola destinava-se a desenvolver em cada indivíduo a cultura geral, de caráter diferenciado, de modo a proporcionar aos futuros dirigentes a necessária capacidade de pensar, de se comportar, de tomar decisões e aos trabalhadores habilidades exclusivamente para o trabalho manual. Podemos constatar o que Gramsci já verificara no início do século, que vâo

${ }^{57}$ Dados levantados e fomecidos pela altura Monica Rogeria. 
se desenvolvendo paulatinamente tipos de escolas voltadas para o desempenho das funçôes instrumentais definidas pelos diferentes ramos profissionais, através de um processo de diferenciação e particularização. Nesse sentido, pode-se afirmar que as escolas profissionais não só não representam um desenvolvimento democrático, mas, ao contrário, perpetuam as diferenças sociais. Gramsci afirma que a escola da sociedade capitalista encerra duas funcões contraditórias: a primeira, formar o cidadão, o homem da polis, sujeito que pensa e decide $e$, a segunda, formar o trabalhador que, tornado objeto, perdendo a sua própria racionalidade, fica condenado a executar tarefas cada vez mais simplíficadas e nada criativas.

A ineficiência do sistema educativo é, como se pode ver, resultante da apatia laboral decorrente dos baixos salários percebidos pelos trabalhadores em educação, pela acomodação ideológica ao sistema perverso e alienanté de idéias vigentes, o desencanto que o fracasso escolar gera no alunado em lunçāo das dificuldades de acesso ao mercado de trabalho futuro e a política de contratacão dos recursos humanos, ainda hoje caracterikada como "curral eleitoral". Não se pode esquecer nem ter medo de denunciar e combater o fato de que o magistério, em geral e, principalmente, o ensino básico, é setor privilegiado de emprego fácil, manipulado pelos políticos de plantão e aproveitado pelos apaniguados políticos que enchem as fileiras do magistério consolidando a lacra da incompetência, muito dificil, posteriormente, de curar. A maior parte dos professores do ensino básico e principalmente os que a ele chegam pelas vias que acabamos de mencionar, não tem, como vimos, nem sequer o primeiro grau completo, muitos nem a primeira fase do primário. Se ainda mais, as oportunidades de cursos de atualização, reciclagem ou melhor dizendo de formação permanente, isto é, a educação contínua, que poderia suprir a educação inicial que não tiveram, é, também, constantemente dificultada, pouco poderemos fazer. Os esforcos, nesse sentido, consumem horas e mais horas de extenuante dedicação por parte de assessores e especialistas em educação para conseguir um padrão mínimo de capacitação e qualificação que, infelizmente, pouco tempo depois, vai por água abaixo, ao sabor do capricho de muitos políticos de 
carreira, pouco interessados no bem comum e no verdadeiro desenvolvimento social.

\section{A EDUCAÇÃO NA CONJUNTURA ATUAL}

O primeiro elemento a ser considerado no contexto da conjuntura atual é o plano econômico do governo, de todos mais ou menos conhecido. Um plano que consegue fazer crescer o PIB. Mas, o problema é que ao aumento da taxa de crescimento do PIB não corresponde um aumento proporcional da taxa de emprego, muito pelo contrário, o desemprego aumenta. Isto significa que; em grandes linhas, o modelo é concentrador de muita renda em mãos de poucos e, em conseqüência, excludente de muitos do direito a gozar os bens mais necessários à simples sobrevivência.

Ao lado deste elemento econômico podemos considerar as características do Novo Estado que as elites estão tentando construir. É comum, hoje, afirmar que o Estado deve se retirar do gerenciamento das áreas de desenvolvimento econômico nas quais historicamente teve papel decisivo; é chegado o momento de privatizar, isto é incumbir a iniciativa privada de assumir também empresas até agora estatais. Isto porque as empresas estatais estão em crise, sendo, portanto a privatização o melhor caminho para reduzir a divida pública, economizar energias administrativas e gerenciais do Estado e, conseqüentemente, equilibrar as contas públicas ${ }^{38}$. E necessário

"reconhecer que não mais cabe ao Estado desempenhar o papel de centro de gravidade e de grande investidor. Nem que se quisesse a coisa seria exequívíl: uma inviabilidade prática condena o modelo. Quais papeis então ficariam reservados ao Estado? $O$ de indutor e de regulador do mercado, o de orientador e de provedor de bens e serviços públicos. Ou seja: não há mais lugar para o formato do Estado tutor e demiurgo dos populistas, nem para o Estado mínimo dos neoliberais; mas há lugar, isto sim, para o Estado ótimo, socialmente necessário, da socialdemocracia contemporânea - uma concepção que proporciona a super- 
ação do assistencialismo paternalista e do fiscalismo asfixiante, ${ }^{\text {,59 }}$

Neste tipo de economia e neste tipo de Fistado proposto eis o que vai acontecendo com a educação

$1^{\circ}$ A Lei de Diretrizes e Bases da Educacão Nacional.

$2^{\circ}$ O Plano Decenal de Educação.

$3^{\circ}$ A nivel de discurso governamental (federal, estadual e municipal) a educação é prioritária, no entanto:

a) 0 nível salarial vigente de praticamente a totalidade das professoras primárias rurais não alcança o salário mínimo.

b) a Universidade passará praticamente um ano (1995) sem poder realizar concursos para provimento das vagas geradas pela corrida irrefreável às aposentadorias prematuras que continuam desfalcando a universidade dos seus quadros docentes e ponto de já haver problemas em muitas delas para dar continuidade normal aos seus cursos.

“... educação é, portanto, um problema político fundamental, e é desse ponto de vista que dever ser encarada. Por motivos recorrentes e nunca resolvidos, não há qualquer interesse em elevar o nivel do ensino, porque as expectativas dos que elaboram e gerenciam a politica educacional e aquelas dos educadores não coincidem, porque são outros - e opostos - os objetivos e intenções: aos primeiros, importa que o rebatho capacite-se apenas para executar rudimentares operações de pensamento que o mantenham nessa condição, aos segundos, interessa a possibilidade de que as pessoas se emancipem também pela educação, o que tem sido visto por todas as polícias sociais como um atrevimento imperdoável. O resultado é que qualidade de ensino virou mera expressão de efeito que faz parte apenas da retórica eleitoreira e das mentiras da propaganda oficial, que, custeada pela sociedade, a ela retoma sob forma de mais ùm engano"

Além de considerar as questões econômicas, sociais e políticas, também é bom olhar para o próprio umbigo ou então, melhor

\footnotetext{
59 Mário COVAS. "A arquitenara do Estado ótimo" in A Folha de São Paulo, 0\%/04/95

${ }^{60}$ Cfr. Paulo Miceli, O quadro (mutto) negro do onsino no Brasil, in A Universidade e o ensino de $1^{\circ}$ e $2^{\circ}$ grous. Campinas, Papirus, 1988.
} 
ainda, se olhar no espelho. Se nós, profissionais da educação nos olharmos no espelho, o que vamos ver nele refletido? Os mais diversos, engraçados, esquisitos e, principalmente, extravagantes (no sentido semântico do termo "que nada fora de lugar, pela via errada"), perdidos e desajustados profissionais.

Paulo Micelli nos apresenta uma tipologia que por interessante transcrevemos quase literalmente.

"...pode-se verificar que cada um deles (os professores) submete-se à remuneraçẫo indigna por motivos próprios:

- Os professores conscientes e ilealistas, sofrendo as agruras da profissão, resistem, mas são cada vez mais raros.

- Os professores de passagem. Os pós-graduados que fazendo da escola pública o campo de estágio, esperam, ansiosamente, pular do trampolim para o, apesar de tudo, privilegiado corpo docente universitário.

- Os professores de licença ou en final de carreira. Afastados por vários motivos aguardam, sofridamente, a aposentadoria, sendo substituídos por estagiários ou professores substitutos.

- Os professores manietados que só não trocam de profissão por absoluta impossibilidade ou mesmo incompetência.

- Os maus profissionajs de outras áreas que, não conseguindo melhor ocupação, dedicam-se ao magistério.

- Finalmente, aqueles que não vivem disso e até se orgulham em apregoar essa condição à frente de alunos e demais colegas. Aqui, uma observação mais longa e, talvez, antipática (ao menos ante os olhos de feministas mais extremadas). Enquanto grande nimero de inulheres lutam valente e conscientemente por sua sustentą̧ão econômica um numero não muito pequeno de professoras faz do magistério uma ostentação de status de duvidosa independência, pois em sociedade machista como a brasileira esta continua sendo uma ocupação feninina aceitável. Assim, acabau pegando algumas aulas para aparentar autosuficiência. Fácil identifica-las: em caso de greve năo participam do movimento porque o marido proíbe, mas apreciam as paralisações que até permitem uma esticada ao clube ou à praia... Alguns homens também fazem parte da espécie: são, em sua maioria, profissionais liberais que resolvem ampliar o orçamento doméstico ou que, entediados com a rotina das noites em casa, encontram forma sutil e eficaz de escapar dela e manter contato com o mundo. Assim como suas companheiras, mantém-se distantes de tudo quanto se relacione ao caráter pro- 
fissional do magistério. ${ }^{61}$

\section{Que POLITICA EDUCATIVA? QUE DIRETRIZES?}

A globalizaçāo do poder e do mercado mundial provocam a reducão do emprego e a reorientação dos mercados a favor dos países centrais. E urgente analisar as novas políticas sociais que, junto com as políticas econômicas, estão cristalizando uma realidade "amistosa para o mercado mundial", antes que uma realidade "amistosa para a população".

Já a privatização supõe uma gigantesca transferência de poder da esfera política (em processo de "descentralização) à esfera econômica (em processo de centralização). Isto, implica, também, numa perda adicional de poder para as maiorias sociais pois, embora de formas perfectíveis, o poder político poderia ser controlado e deveria ser legitimado por elas. Poder-se-ia pressionar nas ruas ou votar pela manutenção de um subsídio, mas não se poderá incidir da mesma forma sobre as políticas protecionistas do Norte ou as estratégias excludentes dos grandes conglomerados do capital mundial.

Todo indivíduo deve ter acesso a uma educação básica relevante, de boa qualidade, num processo de aprendizagem contínuo ao longo da sua vida. Porém, em condiçōes de recursos insuficientes e no marco de certas concepções pedagógicas do processo de aprendizagem, estas políticas, orientadas para os mais pobres, podem se reduzir a prover um pacote compensatório de conhecimentos e destrezas apenas suficiente para lhes permitir sobreviver e melhorar a sua capacidade de aprendizagem. Assim, o resultado é uma concentração de recursos na escola primária o que implica na reduçāo do apoio ao ensino superior e à educaçāo não formal.

A política educativa não pode ser vista como compensatória da pobreza produzida pelas estruturas econômicas, mas deve ela mesma contribuir ao desenvolvimento de novas estruturas eco-

61 Paulo Micelli, id. ibdem. 
nômicas que compensem as tendências à desintegração social e ̀̀ depauperação. Em tal sentido, a preocupaçăo com os segmentos inorgânicos das camadas mais pobres, e o correspondente abando-. no das camadas médias urbanas não supera, ao contrário, consoli. da estruturas que reproduzirão a exclusão das maiorias e deman. darão contínuas intervenções compensatórias.

Assumamos por um momento o objetivo de investir no ensino primário. É indubitável a relevância quando lembramos, por exemplo, dos meninos em e da rua nas cidades do Brasil. Mas o acesso à escola não garante nem a permanência nela nem a aprendizagem de conhecimentos úteis para a vida como produtor e como cidadão. lìm geral existe concordância em que a qualidade do ensino primário dever ser melhorado. Mas isso não se consegue meramente concentrando recursos em novos textos ou na descentralização administrativa do subsistema escolar primário. Para melhorar a qualidade da educação primária é necessário:

i) estender e melhorar a educação inicial que é a principal conquista educativa da regiāo, e contribui de maneira fundamental a compensar o mal inicio dos meninos de lares pobres, assim como a melhorar as oportunidades das mães pará desenvolver as suas próprias atividades;

ii) continuar investindo nos níveis superiores de ensino,

iii) investir na melhoria das capacidades, estatus e salários dos professores, como condição sem a qual as outras intervençōes dirigidas a modificar a qualidade não poderão se realizar eficientemente.

Políticas setoriais como a educaçāo para todos, devem ser enquadradas dentro de uma estratégia dirigida ao desenvolvimento urbano, em lugar de dispersar-se tentando centrar-se nos seg. mentos mais pobres, o que está aparentemente inspirado por modelos de assistencialismo a comunidades rurais isoladas. Mesmo considerado na perspectiva das cúpulas globais, este enfoque está errado. Como o mesmo Banco Mundial conclui no seu informe so" bre o desenvolvimento mundial de 1990, "a pobreza urbarya será o problema mais significativo e politicamente explosivo do próximo 
século". ${ }^{62}$ isso exige enfoques novos para uma realidade urbana da qual América Latina, como a região mais urbanizada do mundo em descnvolvimento, é um exemplo crítico.

\section{Condições para uma Polífica Educativa Orientada ao Desenvolvimento Humano}

A) A educacõo deve estar vinculada desde o comeco com o desenvolvimento econômico, de modo que os novos conhecimentos, destrezas a atitudes tenham a oportunidade de serem aplicados na satisfação das necessidades básicas (trabalho, saúde, nutrição, moradia, meio-ambiente, participação, etc.) como parte do prócesso de aprendizagem.

B) Tendo em conta a insuficiência do setor empresarial capitalista e do setor público para prover oportunidades para todos, deve promover-se o desenvolvimento de uma economia popular arbana.

C) Os progromas devem estar orienlados para a comunidade como umidode elementar. Isto significa trabalhar com e para as comunidades locais em lugar de focalizar segmentos isolados delas (os mais pobros, as meninas em idade escolar, etc.) E necessário prestar atencão tanto às populaçoes rurais como às urbanas mas, numa primeira etapa, pode ser aconselhável centrar-se nos assentamentos urbanos antes do que nos assentamentos dispersos, extremamente carentes de um contexto favoravel para a aprendizagem. A pobrera está se tornando progressivamente um problema urbano. Por volta do ano 2.000 não teremos uma situação de setores marginais ou de zonas segregadas dentro da cidade, mas sim de massas urbanas de pobres "crônicos", e de novos pobres provenientes das camadas médias. A educacão escolar das crianças é insuficiente para conseguir as modificaçoes em padrões culturais e no conhecimento ordinário que o desenvolvimento exige. Todas as modalidades de educaç̃o a aprendizagem devem ser postas a operar ao mesmo tempo, incorporando os diversos elementos da

${ }^{62}$ Ver: Banco Mundial, Urban Policy and Economic Development. An Agewda for the $1990 \mathrm{~s}$, The World Bank, Washington, 1991, p. 4. 
comunidade como elementos ativos no ensino-aprendizagem. A preocupação com os mais pobres raramente vai mais além das preocupações compensatórias. Isto tende a fortalecer o clientelismo em lugar de promover a autonomia dos setoress populares, como deveria esperar-se do empenho com o desenvolvimento humano sustentável. ${ }^{63}$

\section{A Defesa da Escola Pública}

A defesa da escola publica não se resolve combatendo a escola privada. A escola privada tem sua razão de ser. O que devemos defender intransigentemente é a garantia do direito do acesso universal à escola. Isto é, ampliar suficientemente as oportunidades de ingresso e permanência para que as camadas populares possam se beneficiar, em querendo, das vantagens da escolarização. Assim, mantendo, ainda, a pesar de tudo, como referência a estrutura de classes da sociedade em que vivemos, o que devemos combater é qualquer tentativa que vise manter o privilégio de formas de ensino elitistas, destinadas a grupos restritos e exclusi. vos, evitando, também que conteúdos não adequados aos interes." ses das classes populares tomem conta dos currículos.

Se no momento oportuno, a luta pelo direito do Estado tutelar a educação tinha sentido e a palavra laico aplicada ao ensino era uma bandeira de luta de fundamental importância histórica, hoje não parece que seja tão importante acrescentar à diade par. blico e gratuito o terceiro elemento: 具aico Inclusive porque se na época à qual nos referimos laico tinha sabor de oposição à Igreja, hoje, laico tem sabor de oposição a Estado. O Lstado tem obrigação, enquanto administrador e gerente do erário público, de manter e subsidiar a escola, mas a tutela da mesma deve ser conpetência da sociedade através das suas mais variadas formas de organização.

${ }^{63} \mathrm{Cfr}$. José Luis Coraggio. Desarrollo Humano y Polfica educafiva en la iudad Lahimoomeri. cana. Conferenia proferida no IV Semincrio Internacional Lducaçāo Popular e Universida de. João Pessoa-PB. Julho de 1994. 


\section{Bibliografia}

CORAGGIO, José Luis. Desarrollo Humano y Política Educativa en la Ciudad Latinoamericana. Conferência proferida no IV SEMINÁRIO INTERNACIONAL EDUCAÇȦO POPULAR E UNIVERSIDADE. Joðo Pessoa-PB. Julho/1994.

FOLHA DE SAO PAULO 09.04.1995

MICELI, Paulo. "O quadro (muito) negro do ensino no Brasil" in $A$ Universidade e o ensino de $1^{\circ}$ e $2^{\circ}$ graus, Campinas, SP: Papirus, 1988 .

SAVIANI, Dermeval. Ensino Pablico e algumag falas sobre a Universidade. Sx̃o Paulo; Cortez: 1984.

TEIXEIRA, Anisio. "A escola brasileira e a estabilidade social" in Revista Brasileira de Estudos Pedagógicos, vol. XXVIII n ${ }^{\circ} 67,1957$, pp. 3.29. 